\title{
Characteristics of Barium Hexaferrite Nanoparticles Prepared by Temperature-Controlled Chemical Coprecipitation
}

\author{
Jun Young Kwak, Choong Sub Lee ${ }^{\dagger}$, Don Kim, and Yeong Il Kim* \\ Department of Chemistry, Pukyong National University, Busan 608-737, Korea. *E-mail: ykim@pknu.ac.kr \\ 'Department of Physics, Pukyong National University, Busan 608-737, Korea
}

(Received June 29, 2012; Accepted July 24, 2012)

\begin{abstract}
Ba-ferrite $\left(\mathrm{BaFe}_{12} \mathrm{O}_{19}\right)$ nanoparticles were synthesized by chemical coprecipitation method in an aqueous solution. The particle size and the crystallization temperature of the Ba-ferrite nanoparticles were controlled varying the precipitation temperature. The precipitate that was prepared at $0{ }^{\circ} \mathrm{C}$ showed the crystal structure of Ba-ferrite in X-ray diffraction when it was calcined at the temperature above $580{ }^{\circ} \mathrm{C}$, whereas what was prepared at $50{ }^{\circ} \mathrm{C}$ showed the crystallinity when it was calcined at the temperature higher than about $700{ }^{\circ} \mathrm{C}$. The particle sizes of the synthesized Ba-ferrite were in a range of about 20-30 nm when it was prepared by being precipitated at $0{ }^{\circ} \mathrm{C}$ and calcined at $650{ }^{\circ} \mathrm{C}$. When the precipitation temperature increased, the particle size also increased even at the same calcination temperature. The magnetic properties of the Ba-ferrite nanoparticles were also controlled by the synthetic condition of precipitation and calcination temperature. The coercive force could be appreciably lowered without a loss of saturation magnetization when the Ba-ferrite nanoparticles were prepared by precipitation and calcination both at low temperatures.
\end{abstract}

Key words: Ba-Ferrite, Magnetic materials, Precipitation, Mössbauer spectroscopy, Magnetic properties

\section{INTRODUCTION}

Barrium hexaferrite, $\mathrm{BaO} \cdot 6 \mathrm{Fe}_{2} \mathrm{O}_{3}$ of magnetoplumbite type is one of magnetic materials that have been extensively studied since Went et al. first developed. ${ }^{1}$ Due to the high magnetic anisotropy, high coercivity, modest magnetic moment and excellent chemical stability, it has been highly concerned for high-density magnetic recording media. ${ }^{2}$ Since the traditional high temperature solid state synthesis needs heat treatment at temperature higher than $1200{ }^{\circ} \mathrm{C}$, the synthesized ferrite is inhomogeneous in size and hardly had single magnetic domain. Thus the particles are crushed into smaller particles by milling et al. after synthesis. However, the milled particles are not good in magnetic characteristics because of the lattice strain introduced during milling. Therefore, it is essential to crystallize the ferrite at relatively low temperature in order to get homogeneous particles in size and magnetic properties. There have been developed several synthetic methods for low temperature synthesis such as chemical coprecipitation, ${ }^{3-7}$ glass crystallization, ${ }^{8-10}$ sol-gel, ${ }^{11-13}$ microemulsion, ${ }^{14}$ organometallic precursor, ${ }^{15,16}$ and hydrothermal methods. ${ }^{17-19}$ Among them the chemical coprecipitation method has not been well systematically studied since early studies despite it is most basic and relatively simple procedure. Some reports showed that the magnetic properties and particle sizes of Ba-ferrite prepared by chemical coprecipitation could be controlled by doping some transition metal cations. ${ }^{20}$ Previously we reported that Co-ferrite nanoparticles that were prepared by precipitation method in aqueous solution could be varied in size and magnetic properties by controlling simply precipitation temperature. ${ }^{21}$ In this study, we have prepared Ba-ferrite nanoparticles by controlling coprecipitation temperature in simple chemical coprecipitation method and investigated the structural and magnetic properties of those Ba-ferrite nanoparticles.

\section{EXPERIMENTAL}

\section{Synthesis of Nanoparticle Ba-ferrites}

The mixed solution of $0.625 \mathrm{~g} \mathrm{BaCl}_{2} \cdot 2 \mathrm{H}_{2} \mathrm{O}(98.5 \%$, Junsei) and $6.700 \mathrm{~g} \mathrm{FeCl}_{3} \cdot 6 \mathrm{H}_{2} \mathrm{O}$ (98\%, Aldrich) in $40 \mathrm{ml}$ of $0.6 \mathrm{M} \mathrm{HCl}$ was slowly introduced drop-by-drop into 150 $\mathrm{mL}$ of $1.5 \mathrm{M} \mathrm{NaOH}$ solution that was previously adjusted to $\mathrm{pH}$ 11-12 with conc. HCl. During the addition of the mixed solution, the solution of $1.5 \mathrm{M} \mathrm{NaOH}$ was simultaneously added to keep pH 11-12. The temperature of the reaction solution was maintained constant within $\pm 1{ }^{\circ} \mathrm{C}$ with a circulating thermostatic bath and the solution was vigorously stirred. The dark brown precipitate immediately appeared as the mixed solution was added and the reac- 
tion solution was kept stirred for 30 minutes after the mixed solution was added completely. The precipitate was centrifuged at $7000 \mathrm{rpm}$ for 10 minutes and washed with deionized water. The centrifugation and washing were repeated about 10 times until the washed water was free from $\mathrm{Cl}^{-}$ions. The washed precipitate was dried under vacuum at an ambient temperature. The dried precipitate was calcined for 4 hours at various temperatures in air to give crystalline Ba-ferrites.

\section{Apparatus}

$\mathrm{X}$-ray diffraction patterns (XRD) were obtained with Pillips MAX-2000 X-ray diffractometer with $\mathrm{CuK} \alpha$ and $0.02 \% \mathrm{sec}$ scan rate. The transmission electron microscope (TEM) images were taken by Jeol JEM-2010 with a carbon-coated copper grid. The temperature-dependent magnetizations were measured with Lakeshore 7000 series acmagnetosusceptometer at $1 \mathrm{Oe}$ and $1 \mathrm{kHz}$. The magnetic hysteresis curves were obtained with Lakeshore model 7300 vibrating sample magnetometer. The co-precipitation temperature was controlled with JeioTech RBC-30 refrigerated bath circulator with a mixture of ethylene glycol and water. The data of thermal gravimetric analysis (TGA) and differential thermal analysis (DTA) were obtained with Perkin-Elmer TGA7 and DTA7, respectively. The measurements were done under air with the temperature raising rate of $5{ }^{\circ} \mathrm{C} / \mathrm{min}$. Mössbauer spectra were collected by Fast Comtec FG-351 spectrometer with ${ }^{57} \mathrm{Co}$ source doped in metallic Rh that was oscillated in a sinusoidal mode.

\section{RESULTS AND DISCUSSION}

Figs. 1, 2, and 3 show the XRD patterns of the Ba-ferrites and their precursors that were prepared by precipitation at 0,30 and $50{ }^{\circ} \mathrm{C}$, respectively and calcination at various temperatures. When the calcination temperature $\left(T_{c}\right)$ was $750^{\circ} \mathrm{C}$, the XRD patterns confirm the structure of barium hexaferrite for all samples irrespective of the precipitation temperature $\left(T_{p}\right)$. When $T_{\mathrm{c}}$ decreased to $650^{\circ} \mathrm{C}$, however, the sample that was precipitated at $50^{\circ} \mathrm{C}$ does not show the crystallinity of the ferrite, whereas the samples precipitated at 0 and $30^{\circ} \mathrm{C}$ still show the crystal structure of the ferrite. When the temperature further decreased to $600{ }^{\circ} \mathrm{C}$, the sample precipitated at $0{ }^{\circ} \mathrm{C}$ show the structural peaks more intense than those of the sample prepared at $30^{\circ} \mathrm{C}$. Therefore, the crystallization temperature of barium hexaferrite depends upon the precipitation temperature of the precursor when it was prepared by the

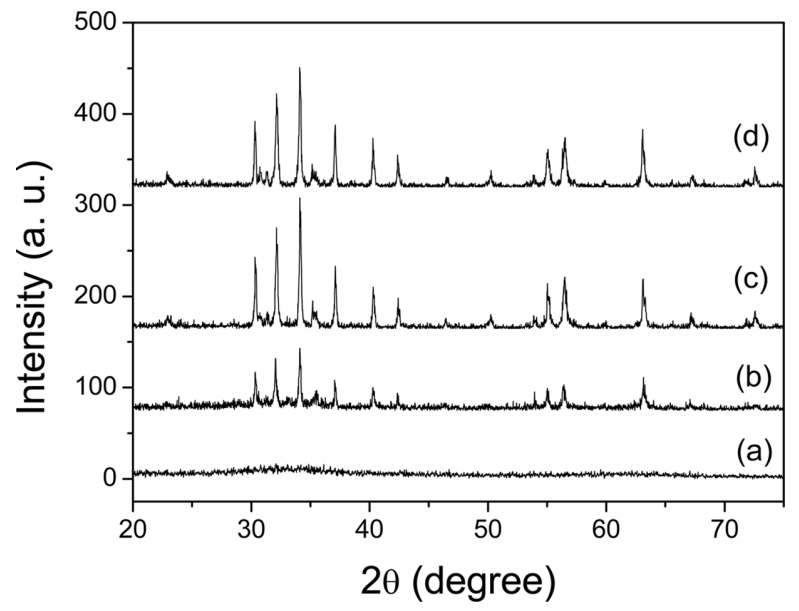

Fig. 1. X-ray diffraction patterns of Ba-ferrites prepared by coprecipitation at $0{ }^{\circ} \mathrm{C}$ and calcination at various temperatures: (a) as precipitated, (b) $600{ }^{\circ} \mathrm{C}$, (c) $650{ }^{\circ} \mathrm{C}$, (d) $750{ }^{\circ} \mathrm{C}$.

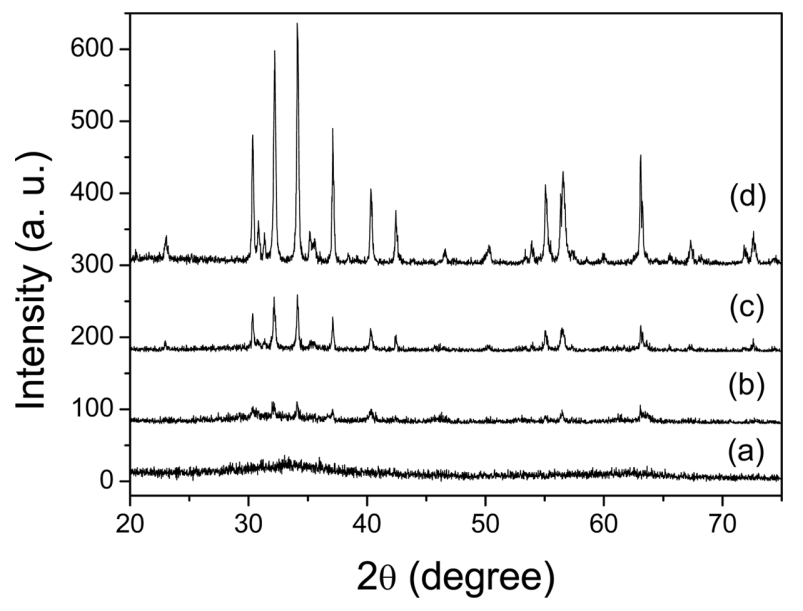

Fig. 2. X-ray diffraction patterns of Ba-ferrites prepared by coprecipitation at $30{ }^{\circ} \mathrm{C}$ and calcination at various temperatures: (a) as precipitated, (b) $600{ }^{\circ} \mathrm{C}$, (c) $650{ }^{\circ} \mathrm{C}$ (d) $750{ }^{\circ} \mathrm{C}$.

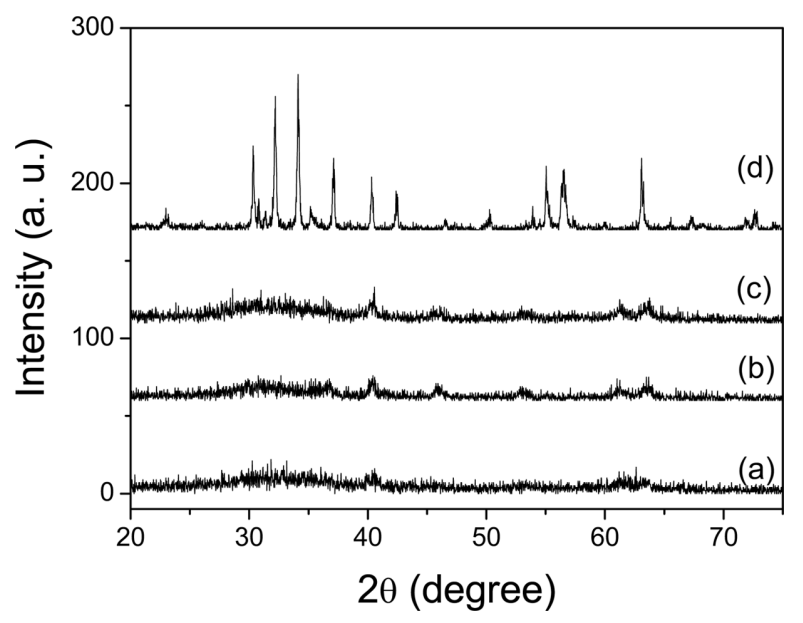

Fig. 3. X-ray diffraction patterns of Ba-ferrites prepared by coprecipitation at $50{ }^{\circ} \mathrm{C}$ and calcination at various temperatures: (a) as precipitated, (b) $600{ }^{\circ} \mathrm{C}$, (c) $650{ }^{\circ} \mathrm{C}$ (d) $750{ }^{\circ} \mathrm{C}$. 
coprecipitation method in basic aqueous solution. The precursors were all apparently amorphous but the precursor prepared at $50^{\circ} \mathrm{C}$ shows some small peaks same as the peaks that appeared when it was calcined at 600 and $650{ }^{\circ} \mathrm{C}$. These peaks do not correspond to any crystal structures of the possible intermediates such as $\alpha-\mathrm{Fe}_{3} \mathrm{O}_{4}, \mathrm{BaO}, \mathrm{Fe}(\mathrm{OH})_{3}$ and $\delta$-FeOOH. There are not much known detail investigations, as far as we know, for the intermediates when barium hexaferrite was prepared by coprecipitation method. The intermediate was usually assumed or identified to be a hydrated hydroxide or haematite. If we assume that our precursors were in simple hydroxide form, the chemical composition can be written as $\mathrm{BaFe}_{12}(\mathrm{OH})_{38}$. When it is calcined to give barium hexaferrite, $\mathrm{BaFe}_{12} \mathrm{O}_{17}$, the loss of weight is theoretically $23.54 \%$. If the hydroxide is hydrated, the weight loss will be more than this. The weight losses of the precursors prepared here, however, were only about $11-13 \%$ as shown in the thermogravimetric analysis (TGA) of Fig. 4(a). Moreover, more than $65 \%$ of the losses occurred below $250{ }^{\circ} \mathrm{C}$. Since the ferric hydroxide was known to transform to the oxide at the temperature of 250$400{ }^{\circ} \mathrm{C},{ }^{22}$ it is hard to say that the precursor is a hydroxide or a hydrated hydroxide. If the weight loss below $250^{\circ} \mathrm{C}$ was due to hydrated water and the slow loss after $250{ }^{\circ} \mathrm{C}$ was due to the hydroxide, it might be reasonable that the precursors were assumed to have mixed compositions of oxide and hydroxide. Then the plausible chemical formula can be $\mathrm{BaO} \cdot \mathrm{xFe}_{2} \mathrm{O}_{3} \cdot(12-2 \mathrm{x}) \mathrm{Fe}(\mathrm{OH})_{3} \cdot \mathrm{yH}_{2} \mathrm{O}$. If we assume that the initial $7-10 \%$ weight loss among the 11$13 \%$ loss is due to hydrated water and next $3-4 \%$ loss was due to the hydroxide from TGA data in Fig. 4(a), $\mathrm{x}$ and $\mathrm{y}$ will be 5.1-5.4 and 3.9-6.2, respectively. The ratio of hydroxide to oxide per Fe atom is about $0.19-0.12$. The precursor prepared at lower temperature has more hydrated water.

The XRD patterns of all samples prepared at three different temperatures did not change and remained amorphous until $T_{c}$ reached above $550{ }^{\circ} \mathrm{C}$ and no haematite phase appeared. If the precipitates were simple mixtures of iron and barium hydroxides, one could expect that haematite phase would appear at about $500{ }^{\circ} \mathrm{C}$. Our result supports that the precipitates were not of a simple hydroxide form. According to the previous studies for the pure Ba-ferrite prepared by chemical co-precipitation method, Haneda et al. showed that the ferrite was crystallized above $800{ }^{\circ} \mathrm{C}$ through the intermediate $\alpha-\mathrm{Fe}_{2} \mathrm{O}_{3}$ at $650{ }^{\circ} \mathrm{C} .{ }^{3} \mathrm{On}$ the other hand, Roos reported the crystallization at $740^{\circ} \mathrm{C}$ without any intermediate phase. ${ }^{4}$ Shin and Kwan who used the modified co-precipitation method of using $\mathrm{Fe}^{2+}$
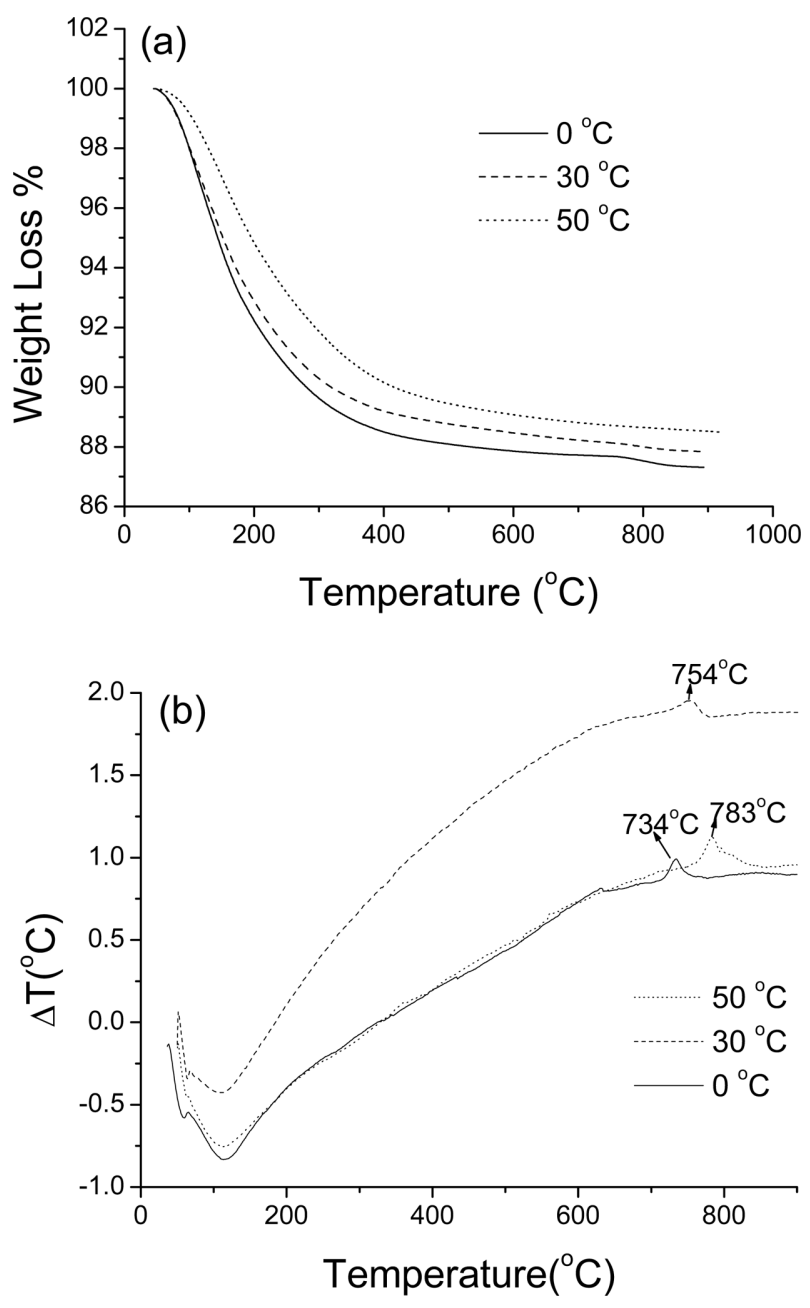

Fig. 4. Thermal gravimetric (a) and differential thermal (b) analyses of the coprecipitates prepared at different temperatures.

and $\mathrm{H}_{2} \mathrm{O}_{2}$ reported that the ferrite was crystallized at the temperature as low as $600{ }^{\circ} \mathrm{C}$ through the intermediate $\alpha$ $\mathrm{Fe}_{2} \mathrm{O}_{3}$ at $550^{\circ} \mathrm{C}$ from initial $\delta$-FeOOH. ${ }^{23}$ Our results showed that the crystallization of Ba-ferrite could be occurred without an intermediate crystal phase from mostly amorphous phase of mixed oxide and hydroxide and the crystallization temperature could be lowered if the precipitation temperature is lowered. This point is confirmed from the differential thermal analysis (DTA) data shown in Fig. 4(b). The exothermic peaks in the DTA data refer to a phase transition of crystallization process since there is no significant weight change at those temperatures. The data clearly indicates that the crystallization temperature of the precursors prepared at different $T_{p}$ s systematically increased as $T_{p}$ increased although the crystallization temperatures do not match with XRD data. The discrepancy between $\mathrm{XRD}$ and DTA comes from nonequilibrium process of DTA. 
Table 1. Unit cell parameters of the synthesized Ba-ferrite nanoparticles

\begin{tabular}{ccccc}
\hline $\begin{array}{c}\text { Coprecipitation } \\
\text { Temperature }\left({ }^{\circ} \mathrm{C}\right)\end{array}$ & $\begin{array}{c}\text { Calcination } \\
\text { Temperature }\left({ }^{\circ} \mathrm{C}\right)\end{array}$ & $a(\AA)$ & $c(\AA)$ & $c / a$ \\
\hline \multirow{2}{*}{0} & 600 & 5.8871 & 23.288 & 3.9557 \\
& 650 & 5.8874 & 23.260 & 3.9508 \\
\hline \multirow{2}{*}{30} & 750 & 5.8903 & 23.236 & 3.9447 \\
& 650 & 5.8866 & 23.179 & 3.9375 \\
& 750 & 5.8880 & 23.191 & 3.9387 \\
\hline \multirow{2}{*}{50} & 900 & 5.8894 & 23.180 & 3.9358 \\
\hline
\end{tabular}

Since DTA was measured during increasing temperature at a constant rate, the process is not at equilibrium. So the peak position depends on the temperature scan rate. When the scan rate increased, the exothermic peak indeed shifted to high temperature.

The lattice parameters that were obtained from XRD data by nonlinear least square method are summarized in Table 1 . The parameter $a$ and $c$ values are in 5.887-5.892, 23.288-23.156, respectively for all samples prepared at $T_{p}$ of $0-50{ }^{\circ} \mathrm{C}$ and $T_{c}$ of $600-900{ }^{\circ} \mathrm{C}$. As $T_{c}$ increased, the value of $a$ increased while that of $c$ decreased. Therefore, the ratio $c / a$ was systematically decreased and close to the value of the known single crystal Ba-ferrite $(c / a=3.936)^{24}$ as both $T_{p}$ and $T_{c}$ increased. The sample that prepared at $T_{p}$ $=0{ }^{\circ} \mathrm{C}$ and $T_{c}=600{ }^{\circ} \mathrm{C}$ shows an elongated structure in $c$ axis with $c / a$ value $0.5 \%$ higher than the known value. The calculated particle sizes of the ferrite are in the range of $35-50 \mathrm{~nm}$ from the Debye-Scherrer equation using the peak of (110) in XRD data. These sizes are coincident with the values from TEM pictures. Fig. 5 show the TEM pictures of the ferrite prepared at $T_{p}=0$ and $30^{\circ} \mathrm{C}$ and $T_{c}=$ 650 and $750^{\circ} \mathrm{C}$. The particle shapes are mostly round and platelet. The samples prepared at $T_{c}=650^{\circ} \mathrm{C}$ showed the sizes of 20-30 and 30-50 nm for $T_{p}=0$ and $30^{\circ} \mathrm{C}$, respectively. When the sample prepared at $T_{p}=30^{\circ} \mathrm{C}$ were calcined to $750{ }^{\circ} \mathrm{C}$, the particles were fused together and barshaped with $50-100 \mathrm{~nm}$ size.

Fig. 6 show the room temperature Mössbauer spectra of the samples prepared at $T_{p}=0$ and $30^{\circ} \mathrm{C}$ and $T_{c}=650^{\circ} \mathrm{C}$. Both of the spectra were deconvoluted to five kinds of sextet peaks that correspond to typical five different kinds of $\mathrm{Fe}$ sites in a M-type Ba-ferrite, i.e. three octahedral, one tetrahedral and one trigonal bipyramidal sites. ${ }^{25}$ The isomer shifts are $0.284-0.390$ and $0.279-0.386$ for the samples of $T_{p}=0$ and $30^{\circ} \mathrm{C}$, respectively. This means that the oxidation state of all $\mathrm{Fe}$ in the ferrite is +3 . Therefore, the spectra confirm that all the samples are in single phase of $\mathrm{Ba}-$

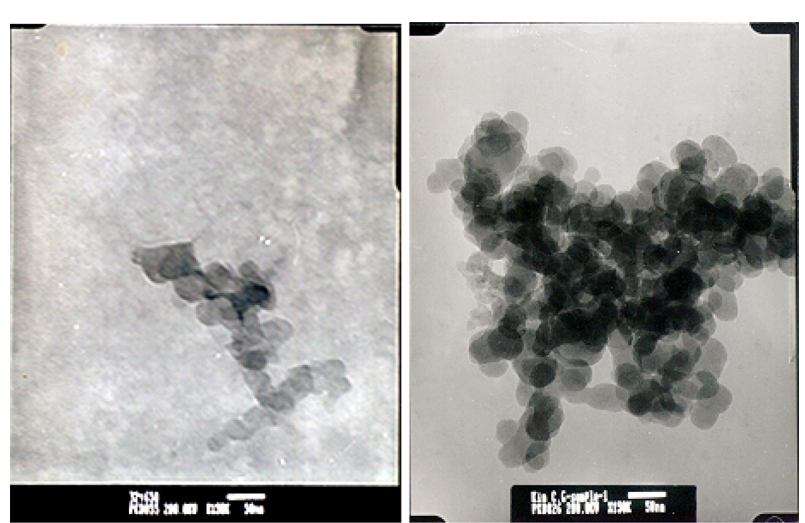

(a)

(b)

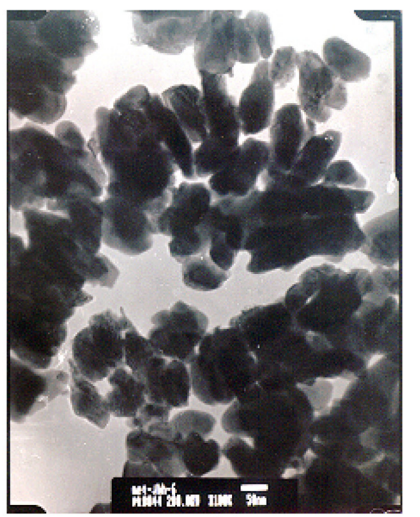

(c)

Fig. 5. Transmission electron micrographs of $\mathrm{Ba}-$ ferrites prepared by coprecipitation and calcination at (a) $0{ }^{\circ} \mathrm{C}$ and $6500^{\circ} \mathrm{C}$, respectively; (b) $30{ }^{\circ} \mathrm{C}$ and $650{ }^{\circ} \mathrm{C}$; (c) $30^{\circ} \mathrm{C}$ and $750{ }^{\circ} \mathrm{C}$. Scale bar indicates $50 \mathrm{~nm}$.

ferrite. Fig. 7 show the Mössbauer spectra of the sample prepared at $T_{p}=0{ }^{\circ} \mathrm{C}$ and $T_{c}=600{ }^{\circ} \mathrm{C}$ measured at room temperature and $80 \mathrm{~K}$. The spectrum at room temperature consisted of a large quadrupole doublet in the middle and some small split peaks outside. Those small split peaks are hardly fitted to sextet peaks because of too low intensity. Since this sample showed the crystallinity of typical Baferrite in XRD (Fig. 1b), the quadrupole doublet repre- 

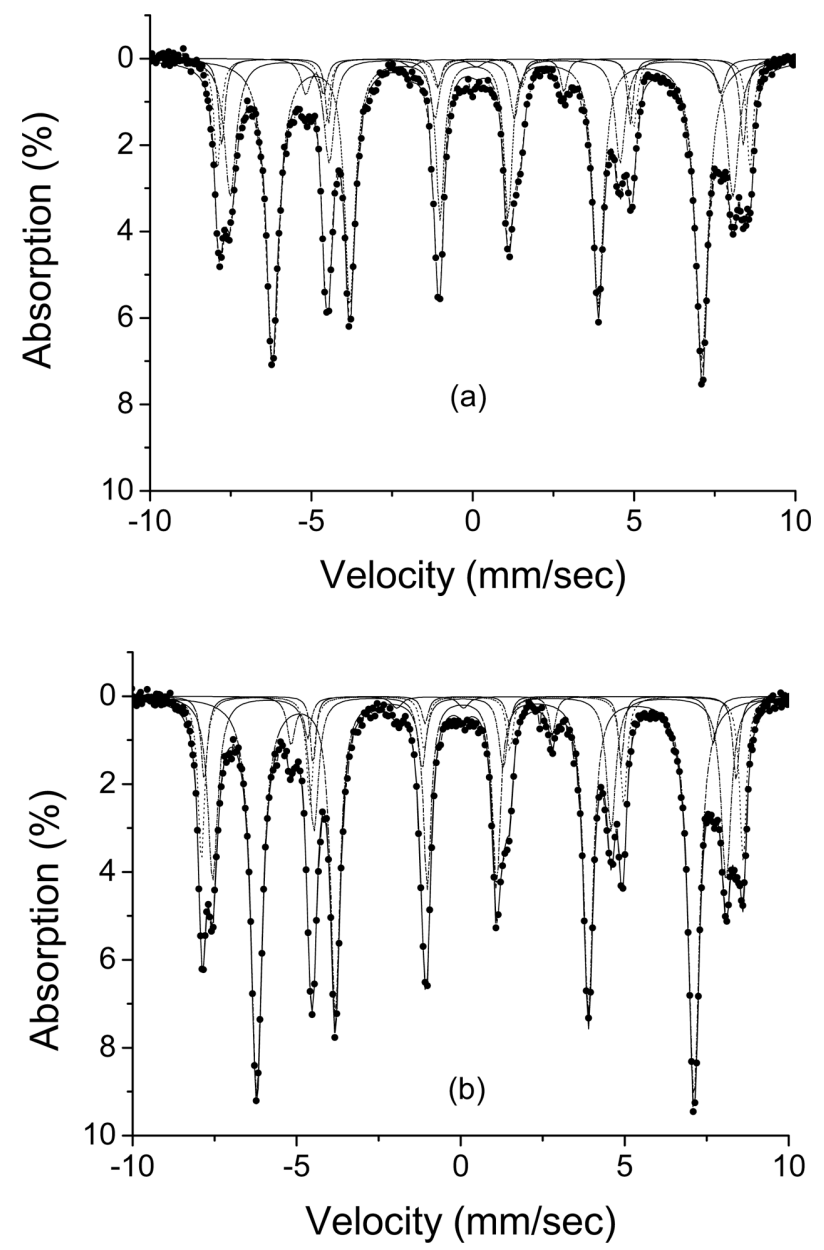

Fig. 6. Mössbauer spectra of Ba-ferrites prepared by coprecipitation at $0{ }^{\circ} \mathrm{C}(\mathrm{a})$ and at $30^{\circ} \mathrm{C}(\mathrm{b})$ and both calcination at $650{ }^{\circ} \mathrm{C}$. Both spectra were measured at room temperature. Dots are measured values and all other lines are fitted values.

sents the superparamagnetic character of the sample due to the small particles whose Neel temperature $\left(T_{N}\right)$ is below room temperature and the small split peaks are due to the relatively larger particles. When this sample was measured at $80 \mathrm{~K}$, the center quadrupole doublet disappeared and the broad sextet peaks appeared. This result implies that the Neel temperature of this sample may be close to $80 \mathrm{~K}$ but the size distribution of the ferrite particles is relatively broad. For the comparison, the Mössbauer spectra of the sample that is precipitated at $0^{\circ}$ and not calcined are shown in Fig. 8. Both the spectra that measured at room temperature and $80 \mathrm{~K}$ consist of quadrupole doublets. Therefore this precursor is composed of all superparamagnetic particles at $80 \mathrm{~K}$ as well as at room temperature. The temperature dependence of magnetic susceptibility for the samples prepared at different $T_{p}$ s is shown in Fig. 9. All the uncalcined samples shows maximum magnetization
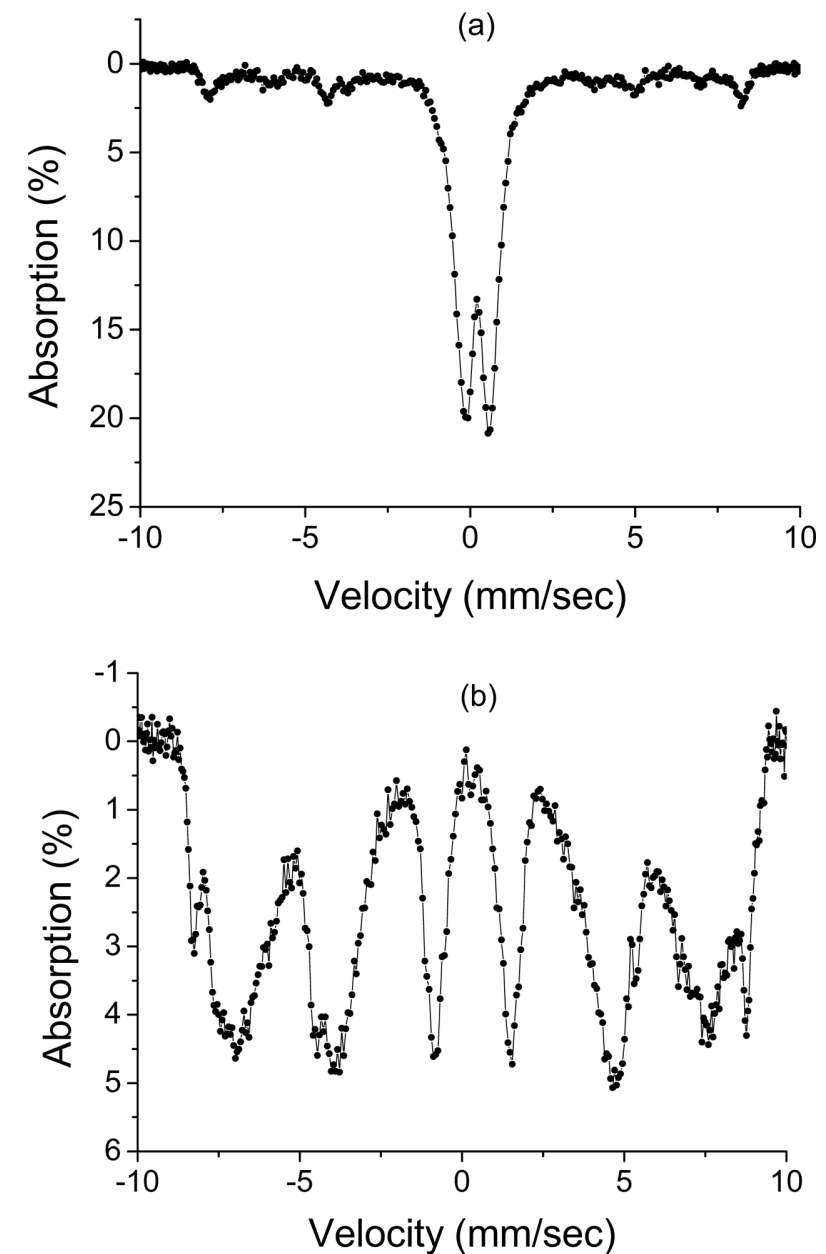

Fig. 7. Mössbauer spectra of Ba-ferrites prepared by coprecipitation at $0{ }^{\circ} \mathrm{C}$ and calcination at $650{ }^{\circ} \mathrm{C}$ : (a) measured at room temperature, (b) measured at $80 \mathrm{~K}$.

with blocking temperatures, at which the superparamagnetic relaxation starts to appear, below $75 \mathrm{~K}$ and the blocking temperature systematically decreased as $T_{p}$ decreased. This indicates that the particle size of the uncalcined samples also decreases as $T_{p}$ decreases because the blocking temperature decreases as the particle size decreases. For the sample that was precipitated at $0{ }^{\circ} \mathrm{C}$ and calcined at $600{ }^{\circ} \mathrm{C}$, the blocking temperature is around $85 \mathrm{~K}$ as shown in Fig. 9(c) although it cannot be well defined. This result is coincident with that from Mössbauer data shown in Fig. 7.

Fig. 10 shows the magnetic hysteresis curves of the Baferrites that were prepared at different $T_{p} \mathrm{~s}$ and $T_{c} \mathrm{~s}$. The magnetization curve does not saturate even at $15 \mathrm{kOe}$ because of the high anisotropic characteristics of Ba-ferrite. So we used the maximum magnetization at the highest applied field herein used $(15 \mathrm{kOe})$ as the saturation magnetization. As shown in the figure, the coercivity $\left(H_{c}\right)$ and saturation 

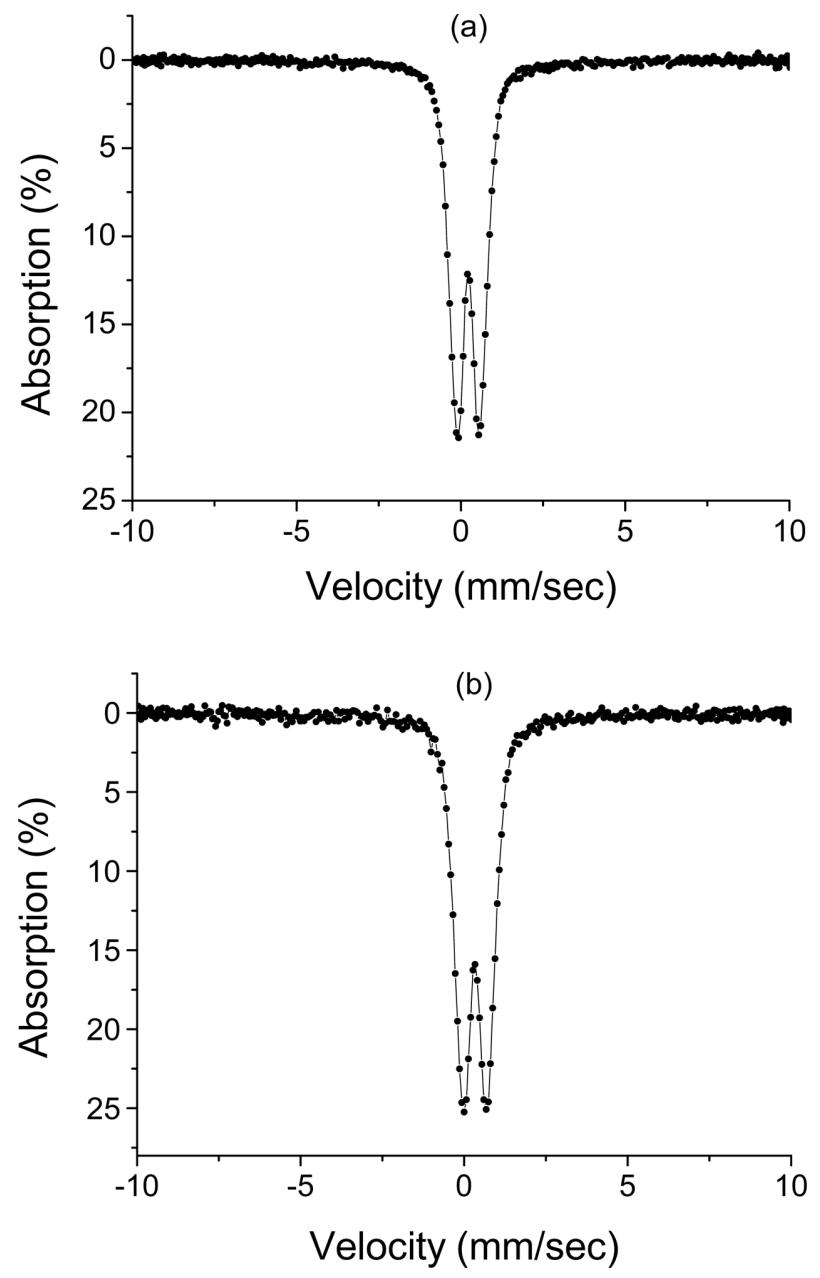

Fig. 8. Mössbauer spectra of Ba-ferrites prepared by coprecipitation at $0{ }^{\circ} \mathrm{C}$ and without calcination: (a) measured at room temperature, (b) measured at $80 \mathrm{~K}$.

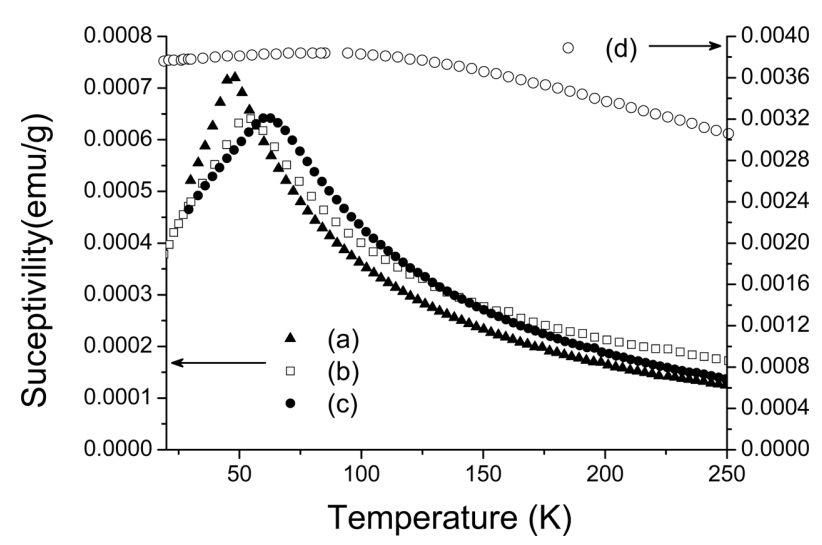

Fig. 9. Temperature-dependent ac magnetic susceptibility for $\mathrm{Ba}$ ferrite prepared by coprecipitation at 0 (a), 30 (b) and $50{ }^{\circ} \mathrm{C}$ (c) without calcination and with calcination at $600{ }^{\circ} \mathrm{C}(\mathrm{d})$.

magnetization $\left(M_{s}\right)$ are appreciably different for the samples prepared at the different precipitation temperatures
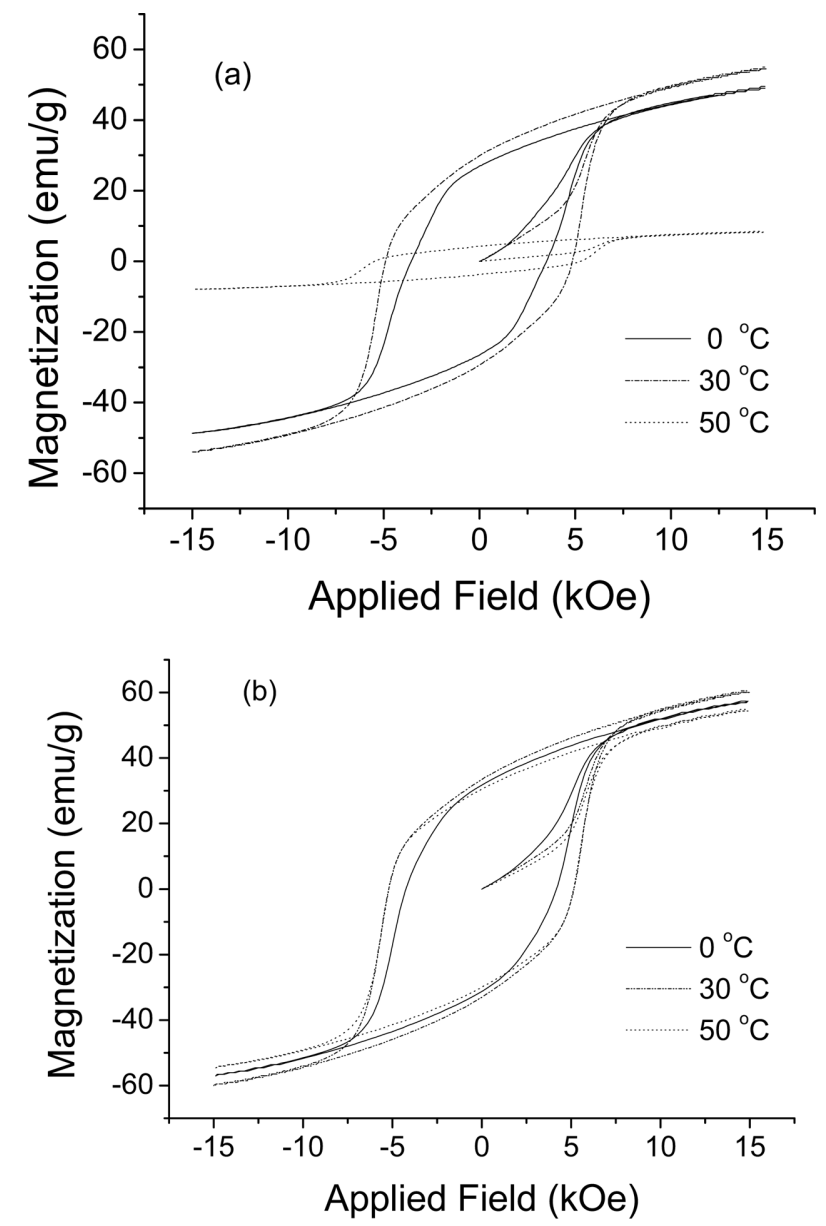

Fig. 10. Magetization vs. applied magnetic field for Ba-ferrites prepared by coprecipitation at various temperatures and calcination at $650{ }^{\circ} \mathrm{C} \mathrm{(a)}$ and $750{ }^{\circ} \mathrm{C}$ (b) (measured at room temperature).

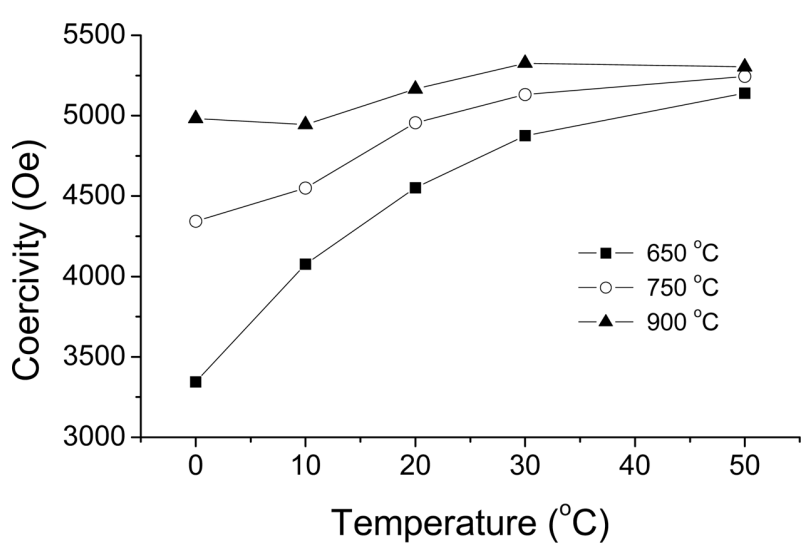

Fig. 11. Coercivity vs. coprecipitation temperature for Ba-ferrites prepared by coprecipitation and calcination at various temperatures.

when the calcination temperature was $650{ }^{\circ} \mathrm{C}$. When the calcination temperature became higher, the difference in $H_{c}$ and $M_{s}$ became smaller. The precipitation temperature dependence of $H_{c}$ and $M_{s}$ for the samples prepared at dif- 


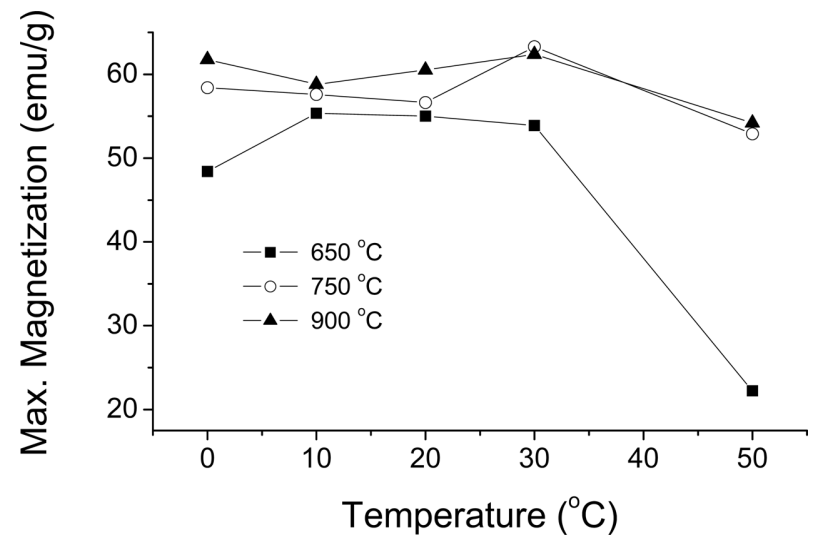

Fig. 12. Saturation magnetization vs. coprecipitation temperature for Ba-ferrites prepared by coprecipitation and calcination at various temperatures.

ferent calcination temperatures are plotted in Fig. 11 and 12. The coercivity increased generally as $T_{p}$ increased regardless of $T_{c}$. The coercivity change by increasing calcination temperature is larger for the sample prepared at lower $T_{p}$. While the coercivity change of the sample prepared at $T_{p}=0{ }^{\circ} \mathrm{C}$ is $1.8 \mathrm{kOe}$ when $T_{c}$ increased from 650 to $900{ }^{\circ} \mathrm{C}$, that for the sample prepared at $T_{p}=50^{\circ} \mathrm{C}$ was only $0.3 \mathrm{kOe}$ at the same $T_{c}$ change. On the other hand, the saturation magnetization was not very dependent on the precipitation temperature except the sample of high precipitation and low calcination temperatures. For the sample prepared at $T_{p}=50{ }^{\circ} \mathrm{C}$ the $M_{s}$ changed from 22 to $54 \mathrm{emu} / \mathrm{g}$ when $T_{c}$ increased from 650 to $900{ }^{\circ} \mathrm{C}$. Therefore, the coercivity of the ferrite could be lowered without the loss of saturation magnetization when it was prepared at low $T_{p}$ and $T_{c}$.

\section{CONCLUSION}

In this study, we have shown, for the first of time as far as we know, that the crystallization temperature of $\mathrm{Ba}-$ hexaferrite nanoparticles could be varied according to the precipitation temperature $\left(T_{p}\right)$ of the precursors when the ferrite were prepared by a simple chemical precipitation method. When $T_{p}$ was $0^{\circ} \mathrm{C}$, the crystallinity in XRD appeared at the calcination temperature $\left(T_{c}\right)$ lower than $600{ }^{\circ} \mathrm{C}$. Whereas, $T_{p}$ was $50^{\circ} \mathrm{C}$, the crystallinity did not appear even at $650^{\circ} \mathrm{C}$. The precipitation precursors were inferred to be mostly in oxide form rather than in hydroxide form to be thought previously. We could synthesize relatively smaller size of Ba-ferrite than previously reported as 20$30 \mathrm{~nm}$ in its diameter when it was prepared at $T_{p}=0{ }^{\circ} \mathrm{C}$ and
$T_{c}=650{ }^{\circ} \mathrm{C}$. The magnetic properties of those Ba-ferrite nanoparticles could be varied depending on $T_{p}$ and $T_{c}$. Especially, the magnetic coercivity strongly depended on the calcination temperature when the precursor was prepared at low $T_{p}$ while there was no such dependence for the precursor prepared at high $T_{p}$. Therefore the coercivity of Ba-ferrite could be lowered without loss of saturation magnetization when the ferrite was prepared at low $T_{p}$ and $T_{c}$. This implies that the drawback of too high coercivity in Ba-ferrite can be complimented by controlling the synthetic condition when the ferrite was applied to various magnetic devices.

Acknowledgments. This work was supported by Korean Ministry of Education through Research Fund (BSRI-982455).

\section{REFERENCES}

1. Went, J. J.; Gorter, E. W.; van Oosterhout, G. W. Philps Tech. Rev. 1951/1952, 13, 194.

2. Sharrock, M.; Carson, L. W. IEEE Trans. Magn. 1995, 31, 2871.

3. Haneda, K.; Miyakama, C.; Kojima, H. J. Am. Ceram. Soc. 1974, 57, 354.

4. Roos, W. J. Am. Ceram. Soc. 1980, 32, 1027.

5. Jacobo, S. E.; Civale, L.; Blesa, M. A.; J. Magn. Magn. Mater. 2003, 260, 37.

6. Hsiang, H.; Yao, R.-Q. Mater. Chem. Phys. 2007, 104, 1.

7. Janasi, S. R.; Emura, M.; Landgraf, F. J. G.; Rodrigues, D. J. Magn. Magn. Mater. 2002, 238, 168.

8. Shirk, B. T.; Buessen, W. R. J. Am. Ceram. Soc. 1970, 53, 192.

9. Lee, C.-K.; Speyer, R. F. J. Mater. Sci. 1994, 29, 1348.

10. Rezlescu, L.; Rezlescu, E.; Popa, P. D.; Rezlescu, N.; J. Magn. Magn. Mater. 1999, 193, 288.

11. Sürig, C.; Hempel, K. A.; Bonnenberg, D. Appl. Phys. Lett. 1993, 63, 2836.

12. Zhong, W.; Ding, W.; Zhang, N.; Hong, J.; Yan, Q.; Du, Y. J. Magn. Magn. Mater. 1997, 168, 196.

13. Xiong, G.; Wei, G. B.; Yang, X. J.; Lu, L. D.; Wang, X. J. Mater. Sci. 2000, 35, 931.

14. Liu, X.; Wang, J.; Gan, L.-M.; Ng, S.-C.; Ding, J. J. Magn. Magn. Mater. 1998, 184, 344.

15. Sankaranarayanan, V. K.; Pankhurst, Q. A.; Dickson, D. P. E.; Johnson, C. E. J. Magn. Magn. Mater. 1993, 120, 73.

16. Sankaranarayanan, V. K.; Khan, D. C. J. Magn. Magn. Mater. 1996, 153, 337.

17. Kumazawa, H.; Cho, H.-M.; Sada, E. J. Mater. Sci. 1993, $28,5247$.

18. Liu, X.; Wang, J.; Gan, L.-M.; Ng, S.-C. J. Magn. Magn. 
Mater. 1999, 195, 452.

19. Mishra, D.; Anand, S.; Panda, R. K.; Das, R. P. Mater. Chem. Phys. 2004, 86, 132.

20. Fang, H. C.; Yang, Z.; Ong, C. K.; Li, Y.; Wang, C. S. J. Magn. Magn. Mater. 1998, 187, 129.

21. Kim, Y. I.; Kim, D.; Lee, C. S. Physica B 2003, 337, 42.
22. Cornell, R. M.; Schwertmann, U. The Iron Oxides; VCH: New York, 1996; p. 314.

23. Shin, H. S.; Kwon, S.-J. Proc. of $6^{\text {th }}$ International Conference on Ferrite; 1992, 1402.

24. JCPDS File No. 84-0757 and 78-0133.

25. Adelsköld, V. Arkiv Kemi. Mineral. Geol. 1938, 12A, 1. 